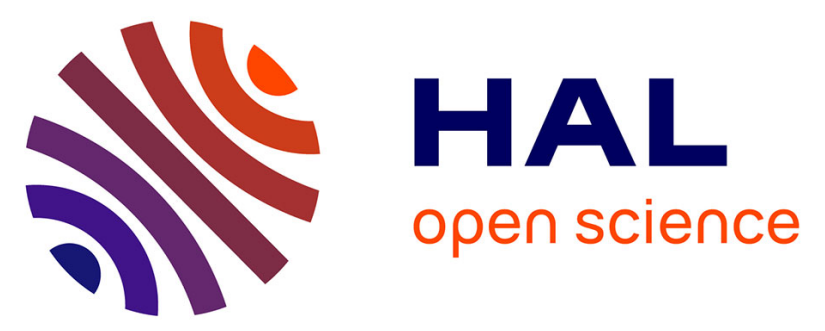

\title{
A macro model based on finite element method to investigate temperature and residual stress effects on RF MEMS switch actuation
}

David Peyrou, Hikmat Achkar, Fabienne Pennec, Patrick Pons, Robert Plana

\section{- To cite this version:}

David Peyrou, Hikmat Achkar, Fabienne Pennec, Patrick Pons, Robert Plana. A macro model based on finite element method to investigate temperature and residual stress effects on RF MEMS switch actuation. Eurosime 2007, Apr 2007, Londres, United Kingdom. pp.525-528. hal-00172956

\section{HAL Id: hal-00172956 \\ https://hal.science/hal-00172956}

Submitted on 18 Sep 2007

HAL is a multi-disciplinary open access archive for the deposit and dissemination of scientific research documents, whether they are published or not. The documents may come from teaching and research institutions in France or abroad, or from public or private research centers.
L'archive ouverte pluridisciplinaire $\mathbf{H A L}$, est destinée au dépôt et à la diffusion de documents scientifiques de niveau recherche, publiés ou non, émanant des établissements d'enseignement et de recherche français ou étrangers, des laboratoires publics ou privés. 


\title{
A Macro Model Based On Finite Element Method To Investigate Temperature And Residual Stress Effects On RF MEMS Switch Actuation
}

\author{
D. Peyrou, H. Achkar, F. Pennec, P. Pons, R. Plana \\ LAAS-CNRS, MINC-M2D Group \\ 7, Av. Colonel Roche, 31077 Toulouse cedex 4, France \\ Email : dpeyrou@laas.fr Phone : +33-561 33 69 30, Fax: +33-561 336208
}

\begin{abstract}
Till nowadays, MEMS design suffers from the lake of efficient and easy-to-use simulation tools considering the complete MEMS design procedure, from individual MEMS component design to complete system simulation. Finite element analysis (FEA) methods offer high efficiency and are widely used to model and simulate the behaviour of MEMS components.

However, as MEMS are subject to multiple coupled physical phenomena at process level, such as initial stress, mechanical contact, temperature, thermoelastic, electromagnetic effects, which highly affects the component, we need to integrate these effects in our model. Doing so, finite element models may involve large numbers of degrees of freedom so that full simulation can be prohibitively time consuming. As a consequence, designers must simplify models or concentrate on interesting results in order to obtain accurate but fast solution.

Some multiphysics' softwares, such as COMSOL [3], allow Reduced Order Modeling (ROM) or macro models which considers the global behaviour of the device. Thus designers can create automatically, for example, their own Simulink (Matlab (C) library from a multiphysics finite element modelization, in order to develop a global behavioural model of the whole component.

This work deals with a Simulink macro model, generated from a three-dimensional multiphysics finite element analysis (FEA) using COMSOL, aiming to investigate the pull-in and pull-out voltage of microswitches.
\end{abstract}

\section{Introduction}

RF Capacitive microswitches are widely studied during the last decade, which demonstrated high isolation, low insertion, large bandwidth and unparalleled signal linearity from dc to $100 \mathrm{GHz}$ frequencies range. Most of these switches uses electrostatic actuation to perform the capacitive shunt for the RF signal (figure 1) because of their low power consumption and their simple manufacturing processes in the clean room techniques. Despite these benefits, RF Mems capacitive switches haven't been yet seen in commercial products for reliability causes, limits in signal power handling and packaging problems. The long term reliability is limited by stiction between the freestanding metal membrane and the dielectric layer coat on the bottom electrode. This stiction is due to both dielectric charging and roughness effects, which will impact the isolation. As low actuation voltage can improve significantly the lifetime, it is essential to design a microswitch able to achieve pull in contact at low voltage (typically $5 \mathrm{~V}$ ).

Therefore, modeling and simulation of electrostatic actuation taking into account the physical phenomena at process level (residual stress [1-2], thermo-mechanicals effects, buckling...), play an important role during the design phase to predict the device's characteristics.

\section{Static modeling of electrostatically actuated microswitches}

We have used the hypothesis of a thin elactic isotropic beam under large deflection with an electrostatic actuation which is modeled on Simulink as a "rigid plate" attached to a spring above a fixed electrode (figure 1).

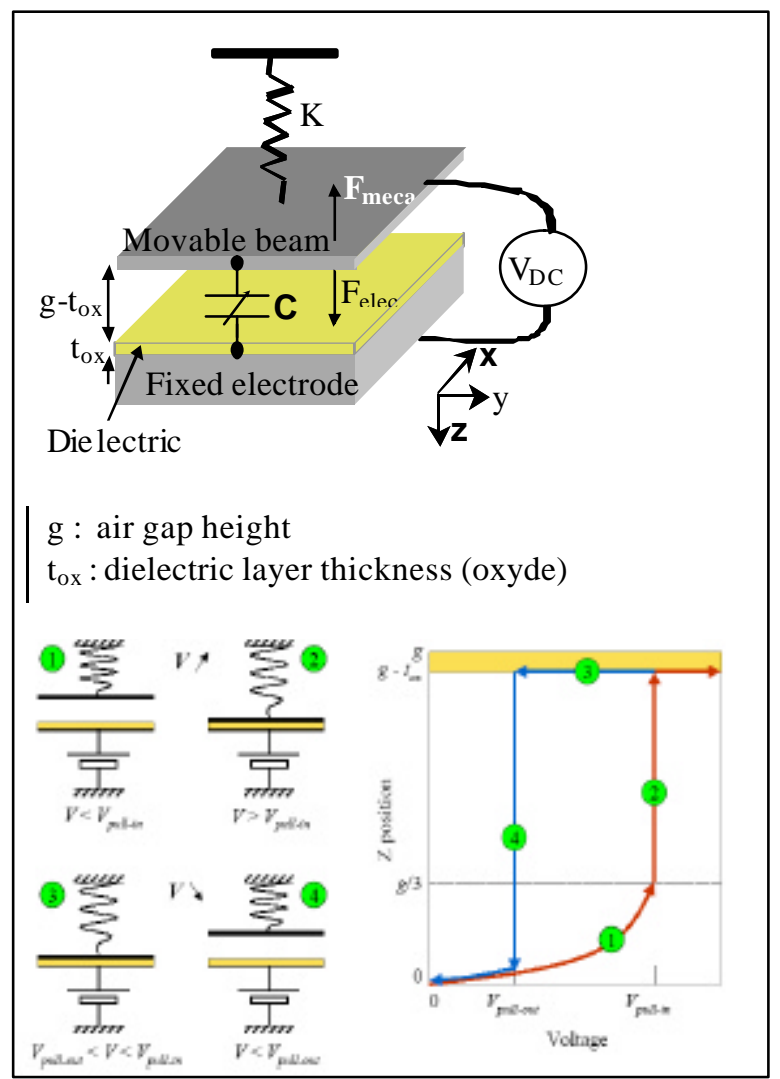

Figure 1 Electrostatic pull-in and pull-out scheme from an elementary model with a spring and rigid plate

In this case, pull-in voltage can be easily obtained from the equilibrium equation between the spring force and the electrostatic force [5], using the following expression: 


$$
\mathrm{V}_{\mathrm{p}}=\sqrt{\frac{8 \mathrm{~kg}_{0}^{3}}{27 \mathrm{e}_{0} \mathrm{~A}}}
$$

With $\left\{\begin{array}{l}\text { A Electrode's area } \\ \mathrm{k} \text { Beam's stiffness } \\ \varepsilon_{0}=8,854 \cdot 10^{-12} \text { (vacuum's permittivity) } \\ \mathrm{g}_{0} \text { initial gap between the beamand the electrode) }\end{array}\right.$

To evaluate the stiffness of the beam, we first extracted the constant stiffness, of an analytical campled-campled beam model as shown in (figure 2), by Castigliano's formulae using the energetic method, as described below.

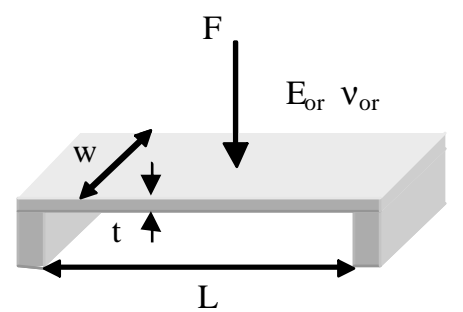

- $\mathrm{w}=40 \mu \mathrm{m}$

- $\mathrm{L}=400 \mu \mathrm{m}$

- $\mathrm{t}=2.7 \mu \mathrm{m}$

- F : Force

- $\mathrm{E}_{\mathrm{or}}$ : Young modulus of gold $=80 \mathrm{GPa}$

- $v_{\text {or }}$ : poisson's ratio of gold $=0.42$

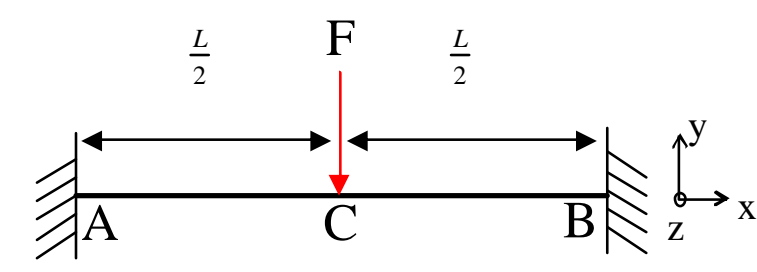

Mechanical actions

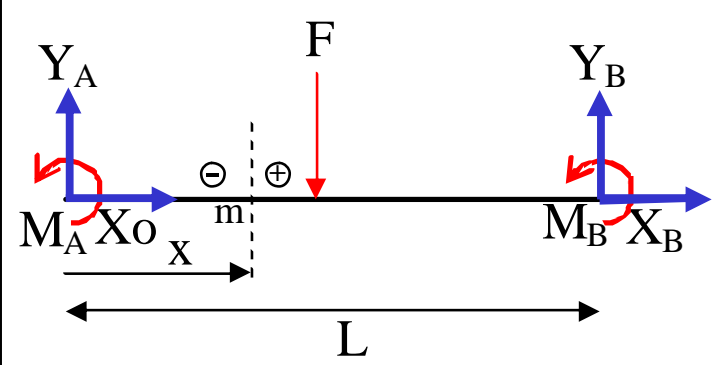

Figure 2 Analytical model definition of a fixed-fixed beam with a punctual load

The adopted sign convention to define the internal forces for the theoretical model represented in (figure 2) is the right convention:
The total energy density in the beam is formulated as:

$$
\begin{aligned}
{\left[\mathrm{W}_{\text {def }}\right]=} & \frac{1}{2} \int_{0}^{\mathrm{L}} \frac{\mathrm{X}_{\mathrm{A}}{ }^{2}}{\mathrm{ES}} \mathrm{dx}+\frac{1}{2} \int_{0}^{\mathrm{L}} \frac{\mathrm{Y}_{\mathrm{A}}{ }^{2}}{\mathrm{GS}} \mathrm{dx} \\
& +\frac{1}{2 \mathrm{EI}} \int_{\mathrm{L} / 2}^{\mathrm{L}}\left(-\mathrm{M}_{\mathrm{A}}+\frac{\mathrm{F}}{2}(\mathrm{~L}-\mathrm{x})\right)^{2} \mathrm{dx} \\
& +\frac{1}{2 \mathrm{EI}} \int_{0}^{\mathrm{L} / 2}\left(\mathrm{M}_{\mathrm{A}}-\frac{\mathrm{F}}{2} \mathrm{x}\right)^{2} \mathrm{dx}
\end{aligned}
$$

So by deriving this energy, we can find all the hyperstatic forces and of course the stiffness of the beam:

$\frac{\partial \mathrm{W}_{\text {def }}}{\partial \mathrm{X}_{\mathrm{A}}}=0 \Rightarrow \mathrm{X}_{\mathrm{A}}=\mathrm{X}_{\mathrm{B}}=0$

$\frac{\partial \mathrm{W}_{\text {def }}}{\partial \mathrm{M}_{\mathrm{A}}}=0 \Rightarrow \ldots . \mathrm{M}_{\mathrm{A}}=-\mathrm{M}_{\mathrm{B}}=\frac{\mathrm{FL}}{8}$

$\frac{\partial \mathrm{W}_{\mathrm{def}}}{\partial \mathrm{F}}=\mathrm{d}=\frac{\mathrm{FL}^{3}}{192 \mathrm{EI}}$ deflectionat the center (pointC)

$\mathrm{K}=\frac{\mathrm{F}}{\mathrm{d}}=\frac{192 \mathrm{EI}}{\mathrm{L}^{3}}$ stiffness of the beam

with $\mathrm{I}=\frac{w t^{3}}{12} \quad$ inertia of the crosssection

The numerical application give us a stiffness: $\mathbf{K}=\mathbf{1 5 , 7 5}$ $\mathbf{N} / \mathbf{m}$. Unfortunately, this theoretical calculation is far from the real stiffness extracted from experimental data, as shown in figure 3 .

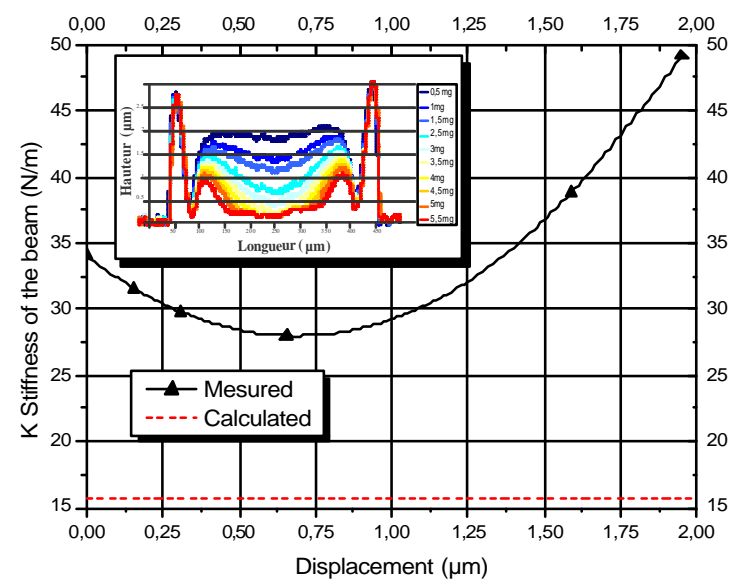

Figure 3 Graph comparing Experimental stiffness to theoretical stiffness

These differences result from the non linear behaviour of the beam's stiffness which was not taken into account in the analytical expression. To solve this problem, a finite element analysis of the beam, loaded with an equivalent electrostatic pressure applied to the entire beam's surface, was performed in order to study the deflection. This electrostatic pressure was not computed 
with a multiphysic simulation but it was introduced as an analytical pressure depending on the deflection of the considered point.
The COMSOL macro model consisted of the structural behaviour taking into account the thermal and residual stress effects $[1-2,4]$ without considering the electrostatic actuation as described in figure 4.

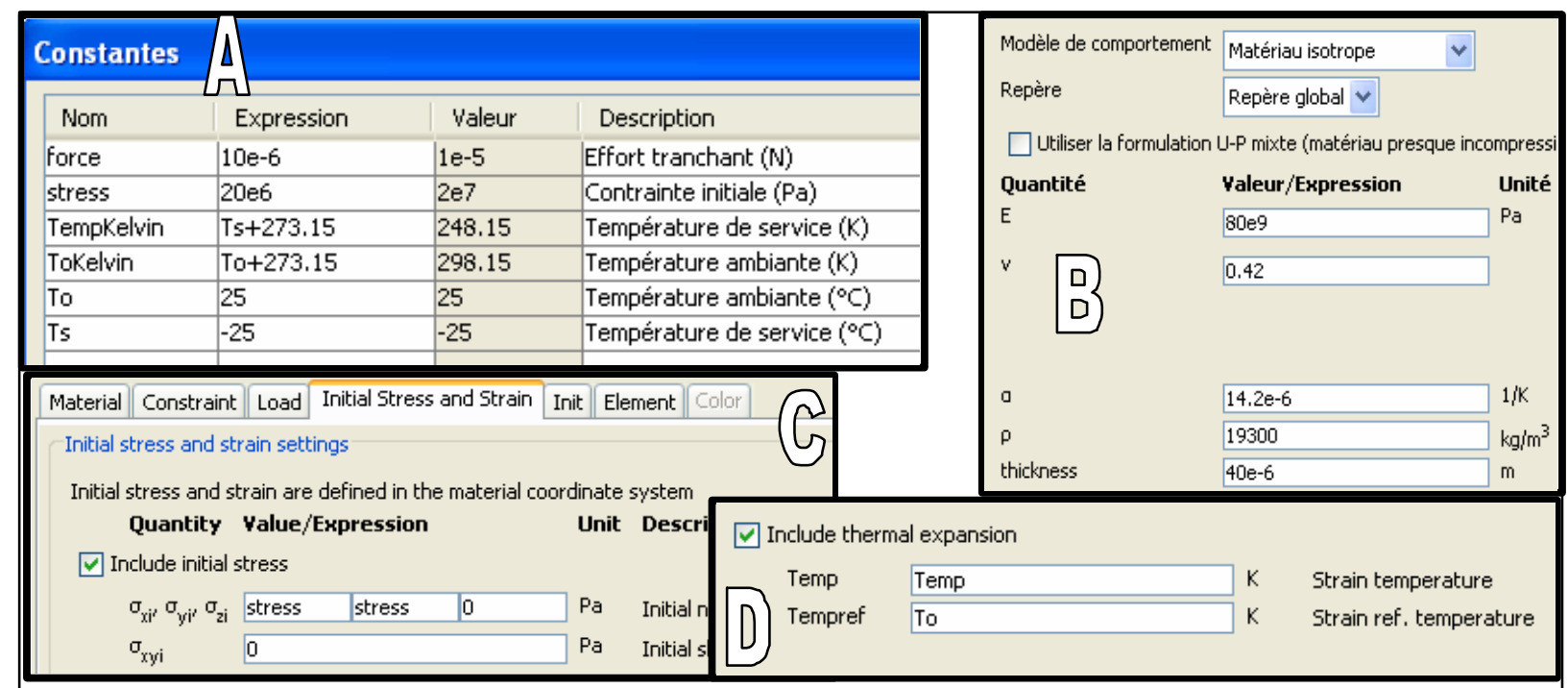

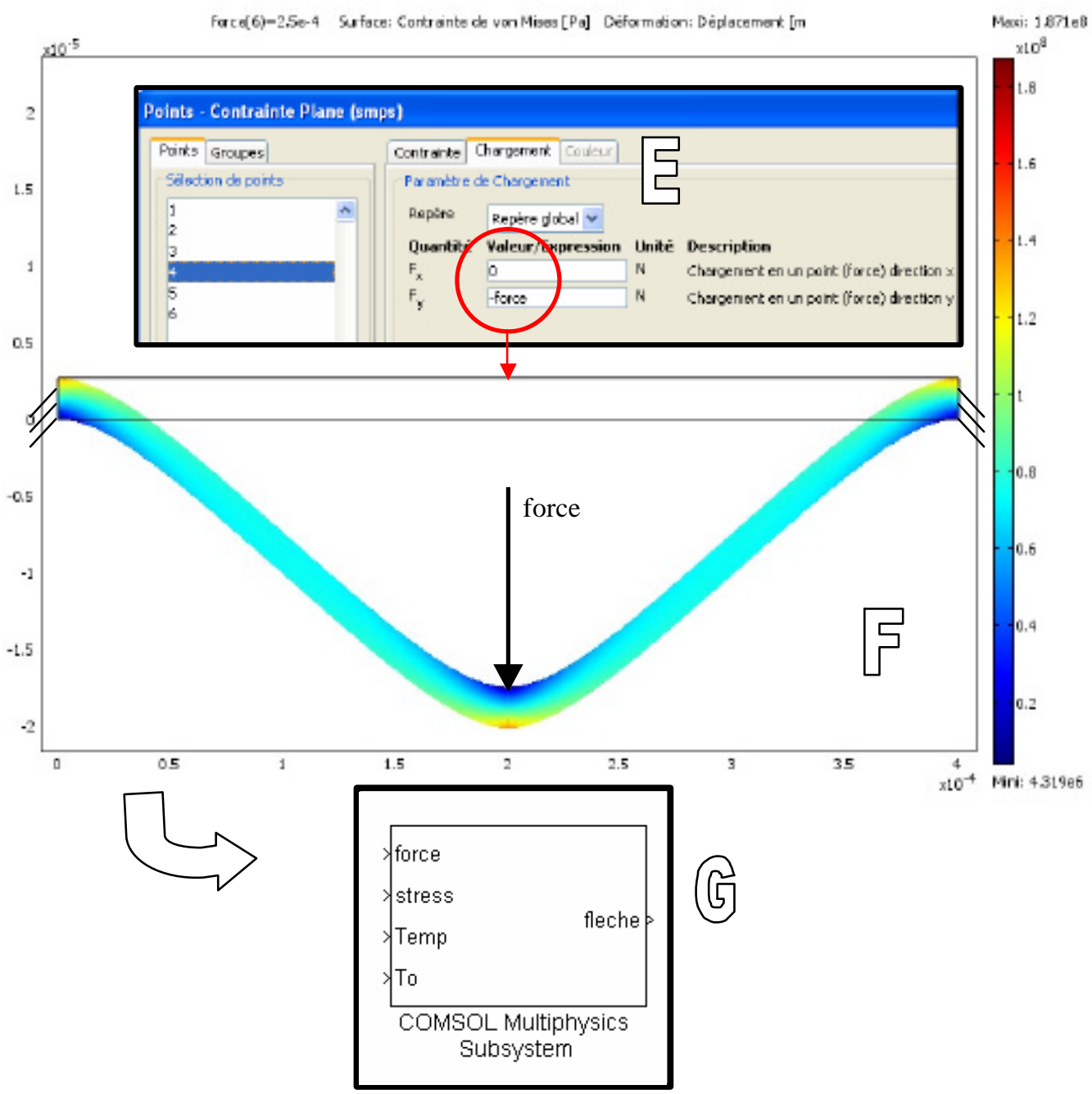

Figure 4 COMSOL Model: (a) Constants' definition - (b) Material's properties - (c) Initial stress - (d) Including thermal expansion- (e) Boundary conditions - (f) Results and postprocessing - (g) Simulink macro model exportation 


\section{Simulation and results}

So, our approach consisted of seperating thermo mechanical and electrostatic domains into sequential analysis. A macro model representing only the thermo mechanical behaviour was integrated in a Simulink scheme to perform the electrostatic actuation (figure 5).

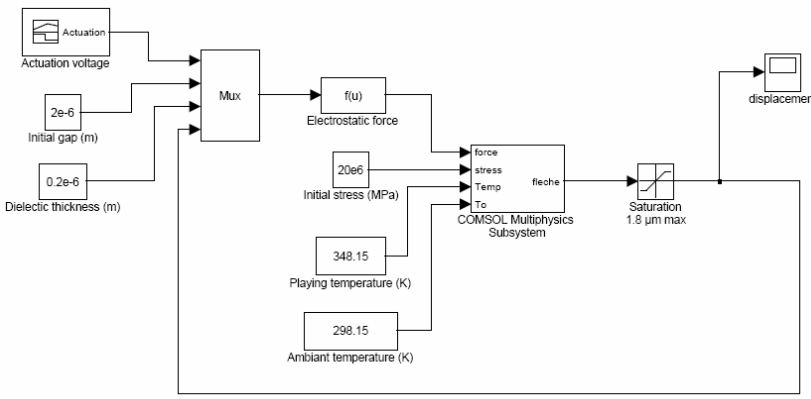

Figure 5 Simulink's model scheme

The main difficulty in setting up the pressure was to take into account the variation of the surface's normal vector during the deformation.

By using NANSON's formula which allows to connect an element of surface oriented in the non deformed configuration, in an element of area in the deformed configuration (with the convention vector in bold):

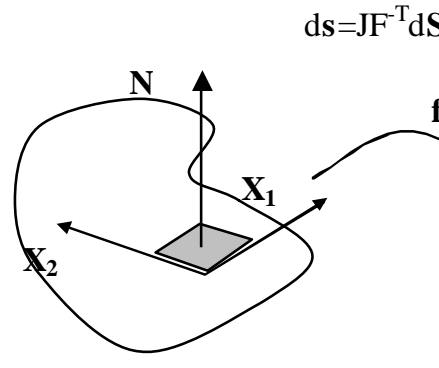

$\mathbf{d S}=\mathrm{d} \mathbf{S} \mathbf{N}$

Initial configuration
Deformed configuration

With $\mathrm{J}$, the jacobian of the vectorial transformation $\mathrm{f}$ to cross from the initial state to the deformed state and $\mathrm{F}$ the strain gradient, we have:

$$
\mathrm{F}=\overline{\overline{\operatorname{grad}}} \mathbf{f}=\frac{\partial f_{i}}{\partial X_{j}}=\frac{\partial x_{i}}{\partial X_{j}}=\left(\begin{array}{ll}
F_{11} & F_{12} \\
F_{21} & F_{22}
\end{array}\right)
$$

So, for our application, it is enough to implement the value of the surface load according to the initial configuration in COMSOL. According to the formula of NANSON, this pressure is obtained by:

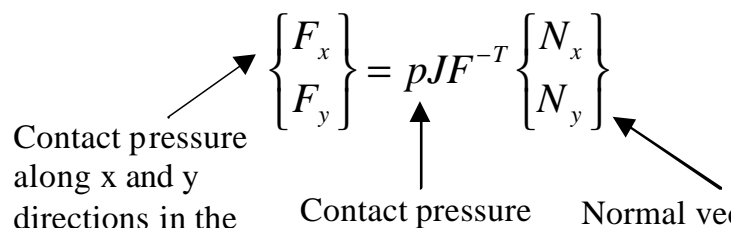

directions in the
initial configuration
This method allows us to easily implement residual stress and various operational temperatures in the macro model in order to study the performance of microswitches.

The simulations showed that both residual stress and temperature significantly affects the pull-in and pull-out voltages. In fact, the analysis shows that the change in the operating climat from room temperature to $-50{ }^{\circ} \mathrm{C}$ or an increase in the residual stress state, has to be overcomed by higher pull-in and pull-out voltages (figure 6).

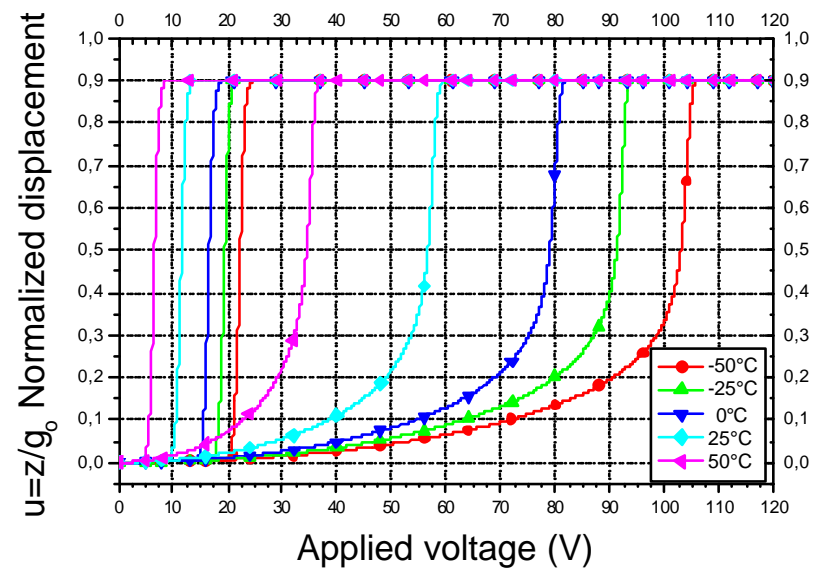

Figure 6 Rigid-plate displacements versus actuation voltage taking into account the non-linear stiffness of the beam (hysteresis).

\section{Conclusions}

This original approach permits us to reduce the calculation time and by consequence opens for us a new perspective to improve the structural model, by taking into account the real profile of the microswitches as discussed in a previous work, where we validated a reverse engineering technique.

\section{Acknowledgments}

The authors would like to acknowledge the Délégation Générale de l'Armement (DGA) for its support through the contract 0134032 .

\section{References}

1. W. Fang and J.A. Wickert, "Determining mean and gradient residual stresses in thin films using micromachined cantilevers", J. Micromech. Microeng. 6 (1996) p301-309

2. Youn-Hoon Min, Yong-Kweon Kim, "In situ measurement of residual stress in micromachined thin films using a specimen with composite layered cantilever", J. Micromech. Microeng. 10 (2000) p314321

3. http://www.comsol.com/

4. D. Peyrou et Al. "Multiphysics Softwares Benchmark on Ansys / Comsol Applied For RF MEMS Switches Packaging Simulations", Eurosime 2006, Côme (Italie), 24-26 april 2006, 8p

5. G. M. Rebeiz «RF MEMS Theory, Design and Technology »,édition Wiley, 2003, p38 